\title{
Association of open communication and the emotional and behavioural impact of medical error on patients and families: state-wide cross- sectional survey
}

\author{
Julia C Prentice (D) , ${ }^{1}$ Sigall K Bell, ${ }^{2,3}$ Eric J Thomas, ${ }^{4}$ Eric C Schneider, ${ }^{5}$ \\ Saul N Weingart, ${ }^{6}$ Joel S Weissman, ${ }^{7}$ Mark J Schlesinger ${ }^{8}$
}

- Additional material is published online only. To view please visit the journal online (http://dx.doi.org/10.1136/ bmjqs-2019-010367).

For numbered affiliations see end of article.

\section{Correspondence to} Dr Julia C Prentice, Research and Analysis, Betsy Lehman Center for Patient Safety, Boston, MA 02116, USA; Julia.Prentice@state.ma.us

Received 16 September 2019 Revised 23 December 2019 Accepted 3 January 2020 Published Online First 20 January 2020

\section{Sinked}

- http://dx.doi.org/10.1136/ bmjqs-2020-010855

Check for updates

(C) Author(s) (or their employer(s)) 2020. No commercial re-use. See rights and permissions. Published by BMJ.

To cite: Prentice JC, Bell SK, Thomas EJ, et al. BMJ Qual Saf 2020:29:883-894.

\begin{abstract}
Background How openly healthcare providers communicate after a medical error may influence longterm impacts. We sought to understand whether greater open communication is associated with fewer persisting emotional impacts, healthcare avoidance and loss of trust.

Methods Cross-sectional 2018 recontact survey assessing experience with medical error in a 2017 random digit dial survey of Massachusetts residents. Two hundred and fifty-three respondents self-reported medical error. Respondents were similar to nonrespondents in sociodemographics confirming minimal response bias. Time since error was categorised as $<1,1-2$ or 3-6 years before interview. Open communication was measured with six questions assessing different communication elements. Persistent impacts included emotional (eg, sadness, anger), healthcare avoidance (specific providers or all medical care) and loss of trust in healthcare. Logistic regressions examined the association between open communication and long-term impacts.

Results Of respondents self-reporting a medical error 3-6 years ago, 51\% reported at least one current emotional impact; $57 \%$ reported avoiding doctor/facilities involved in error; $67 \%$ reported loss of trust. Open communication varied: $34 \%$ reported no communication and $24 \%$ reported $\geq 5$ elements. Controlling for error severity, respondents reporting the most open communication had significantly lower odds of persisting sadness ( $O R=0.17,95 \% \mathrm{Cl} 0.05$ to $0.60, p=0.006)$, depression ( $O R=0.16,95 \% \mathrm{Cl} 0.03$ to $0.77, p=0.022$ ) or feeling abandoned/betrayed $(\mathrm{OR}=0.10,95 \% \mathrm{Cl} 0.02$ to $0.48, p=0.004$ ) compared with respondents reporting no communication. Open communication significantly predicted less doctor/facility avoidance, but was not associated with medical care avoidance or healthcare trust.

Conclusions Negative emotional impacts from medical error can persist for years. Open communication is associated with reduced emotional impacts and decreased avoidance of doctors/facilities involved in the error. Communication and resolution programmes could facilitate transparent conversations and reduce some of the negative impacts of medical error.
\end{abstract}

\section{What this study adds}

- Emotional impacts from error, healthcare avoidance behaviours and loss of trust in healthcare system can persist for years after an error.

- Greater open communication about the error is associated with significantly reduced feelings of sadness, depression, abandonment/betrayal and the avoidance of doctors and facilities involved in the error.

- Communication and resolution programmes, not yet widely implemented, could increase open communication, reducing some of the negative impact of medical error on patients and families.

\section{INTRODUCTION}

Medical errors are common. ${ }^{1-3}$ One in four adult Americans report experience (either themselves or someone close to them) with a medical error within the previous 5 years. ${ }^{45}$ Research has illuminated the nature and causes of errors, but we know far less about the resulting impact on patients and families and how those consequences might be mitigated.

Medical errors are associated with significant emotional, financial, physical and sociobehavioural impacts, including reduced trust and willingness to seek healthcare. ${ }^{6-9}$ But these studies have small sample sizes, study shortterm effects or are limited by selection bias, making it difficult to generalise the results and influence policy and practice. How providers and organisations 
respond to patients and families after an error likely influences the extent or persistence of these impacts. Despite increasing emphasis on transparency after medical error, disclosure to patients is infrequent and incomplete, potentially compounding harm. ${ }^{10-16}$ Past research on communication after error has focused on narrow patient populations, hypothetical situations, evaluations of specific programmes facilitating disclosure and apology, or outcomes such as malpractice claims. ${ }^{79} 13$ 17-22 The long-term impact of communication about the error on patients' well-being or subsequent health-seeking behaviours is unknown.

This study examines the emotional, physical and healthcare avoidance impacts of errors self-reported by patients and family members as well as the relationship between open communication about medical error and these impacts. 'Open communication' refers to the extent to which patients and families perceive that providers and healthcare teams disclosed to them information about the error and invited discussion. Starting with a large random sample, we surveyed Massachusetts adults who perceived a medical error experience to: (1) assess the initial physical and emotional impact; (2) measure the emotional and physical impacts as well as healthcare behaviours and attitudes that persist at the time of the survey; (3) characterise respondents' perceptions of communication with providers and care teams regarding the error; and (4) examine the relationship between open communication and impacts. We hypothesised that respondents who experienced more open communication would report fewer persisting emotional impacts, healthcare avoidance and loss of trust.

\section{METHODS}

\section{Sample}

A sample of adult residents of Massachusetts aged 18 or older self-reporting medical error was generated through two telephone surveys in 2017 and 2018. In 2017, the research firm SSRS fielded the Massachusetts Health Insurance Survey (MHIS) on behalf of the state's Center for Health Information and Analysis. MHIS used a random-digit dial design to reach 5001 Massachusetts households. The instrument included questions from the Betsy Lehman Center for Patient Safety, another state agency, as to whether respondents had experience with a medical error during the previous 5 years (online supplementary appendix A table 1). These are medical errors that respondents perceived to have occurred and the errors have not necessarily been reviewed by clinicians or corroborated in medical records. All respondents were asked if they were willing to be recontacted and in 2018, SSRS recontacted respondents who had agreed (online supplementary appendix A Figure 1). ${ }^{23}$

This study focuses on English-speaking respondents who perceived a medical error in the 2018 survey. These include two subsets of respondents: (A) those who perceived an error on the 2017 survey and agreed to be recontacted and (B) a randomised subset of those not reporting an error in 2017, but who subsequently indicated they had experienced an error in the recontact survey. Online supplementary appendix A includes descriptions of the sampling methodology and analyses examining potential selection bias.

\section{Survey instrument development and patient and public involvement}

For survey design, the Betsy Lehman Center convened an expert advisory group, including the authors, and drew on existing literature on public awareness of medical error. ${ }^{45}{ }^{24}$ The Research Task Force for the Collaborative for Accountability and Improvement, a national advisory group of researchers, clinicians, safety experts, risk managers and patients and families, provided further survey design input. ${ }^{25}$ Eight respondents self-reporting a medical error in 2017 provided cognitive testing for the survey instrument, but were not included in the study sample.

\section{Survey questions}

The instrument (online supplementary appendix A table 1 and appendix E) comprised 30 quantitative and qualitative questions and administered via phone.

\section{Medical error characteristics}

Respondents were asked who the error affected, whether the respondent was responsible for the medical care of the individual who experienced the error, the type of facility where the error took place and when the error occurred $(<1,1-2,3-6$ years prior to the survey).

\section{Impact of errors}

We asked subjects to describe the physical (death or loss of function) and emotional (sadness, anxiety, anger, depression, or feelings of abandonment or betrayal by the doctor) impacts experienced at the time of the error ('initial') and at the time of the survey ('persisting'), based on previous literature. ${ }^{6-8} 1316 \mathrm{We}$ also queried whether respondents avoided the doctors or facilities involved in the error or medical care in general (never, sometimes or always). In addition, we examined respondents' reports of loss of trust in healthcare compared with their attitudes before the error and asked participants to report financial impacts (increased expenses or lost earnings) related to the error. ${ }^{26-29}$

\section{Open communication and apology}

We assessed open communication based on respondent report of whether the care team or anyone at the place where the error occurred: (1) acknowledged the error; (2) spoke openly and truthfully about it; (3) spoke about it in a manner easily understood; (4) conveyed information about the health consequences 
of the error; (5) welcomed questions about the error; or (6) provided opportunities to express feelings about the error. An equal-weighted count of these elements was used but alternative specifications are explored in more detail in online supplementary appendix B. To examine the threshold effects related to open communication, we categorised respondents into four strata: no reported communication, communication involving one to two elements, three to four elements or five to six elements.

The survey separately asked if respondents who had communicated with providers had received an explicit apology for the error. To distinguish between open communication and apology, we kept this potential confounder separate.

The survey also separately asked respondents about their overall satisfaction with their communication about the error and whether they felt cared for by the care team. These questions were used to test the construct validity of the open communication index (online supplementary appendix B). Finally, respondents who reported the error was acknowledged by someone at the place where the error occurred were asked whether they received information about a formal review or investigation or whether they received an explanation of actions taken to prevent similar medical errors in the future. These two elements were not included in the open communication index because only $3 \%(n=8)$ and $7 \%(n=17)$ of all respondents self-reporting an error reported said yes to each of these questions, respectively.

\section{Statistical analyses}

We used STATA V.15.0 (StataCorp, College Station, TX) for analyses. ${ }^{30}$ Missing responses for each question were dropped before running statistical analyses; unless noted, non-responses comprised $<5 \%$ of the sample. We used $\chi^{2}$ tests to compare self-reported error impact between respondents experiencing recent ( $<1$ year) and older errors (3-6 years ago) and to compare error impact at the time of survey between respondents who experienced different levels of open communication.

The association between the extent of open communication and impacts of perceived error persisting at the time of the survey was estimated using separate logistic regression models for three outcomes of interest: emotional harms, healthcare trust and healthcare avoidance. Our models controlled for error attributes or respondent characteristics that might be associated with both error impact and open communication. These included the financial and initial physical impacts of the error, who experienced the error (patient vs family member), whether the respondent was responsible for the medical care of the family member who experienced the error, how long since the error occurred, respondents' education level and gender.
To distinguish the impact of open communication, as we have defined it above, from previously studied aspects of communication, such as explicit apologies, it is useful to incorporate measures of each into the regression models. Because apologies themselves may be induced by more robust forms of communication between provider and patient, including apology as a control variable may understate the full impact of open communication. Conversely, the healthcare system could perfunctorily apologise but not engage the patient in a comprehensive discussion about the perceived error, leaving patients to question the sincerity of the apology. Consequently, we report here regression models that both include and excluded apology as an explanatory variable.

Finally, to examine whether our results were impacted by respondents who did not experience the error themselves, and were not closely connected to the individual who experienced the perceived error, we ran sensitivity analyses on this subset of respondents. We excluded respondents who reported the perceived error happened to an extended family member (eg, aunt) and they were not responsible for the medical care of the individual who experienced the error. Full results are included in the online supplementary appendix D tables 10 and 11.

\section{RESULTS}

\section{Survey response}

The recontact survey generated a sample of 253 respondents who perceived a medical error. The American Association Public Opinion Research R3 response rate $^{31}$ is $41 \%$ for the recontact survey only and $10.1 \%$ when multiplied by the MHIS 2017 response rate of 24.6\% (online supplementary appendix A: Response Rate Calculations). The margin of error is \pm 8.7 percentage points. ${ }^{32}$ Among respondents who selfreported a medical error in 2017, we found no significant differences in sociodemographic characteristics or experiences with medical error between respondents who agreed to recontact and those who declined (online supplementary appendix A table 2). The sociodemographic and medical error characteristics of respondents who self-reported medical errors in the MHIS and then completed the 2018 recontact survey did not differ significantly from respondents who did not complete the recontact survey. SSRS was able to recontact a higher percentage of respondents who reported a medical error in their own care than those who reported an error that happened to a household or family member (online supplementary appendix A table 3).

\section{Subject and error characteristics}

Of the 253 respondents who perceived a medical error, nearly $60 \%$ reported the error happened to themselves, a spouse or their child. Almost half reported the error occurred 3-6 years ago. Fewer than half of 
Table 1 Descriptive statistics of respondents reporting experience with a medical error and medical error characteristics

\begin{tabular}{ll}
\hline Demographics & $\mathrm{n}(\%)$ \\
\hline Gender $(\mathrm{n}=253)^{*}$ & \\
Male & $109(43)$ \\
Female & $144(57)$
\end{tabular}

Education ( $\mathrm{n}=237)$

$\begin{array}{lc}\text { Less than high school } & 27(11) \\ \text { High school } & 55(23) \\ \text { Associates degree or some college } & 69(29) \\ \text { College graduate } & 47(20) \\ \text { Postgraduate } & 39(17) \\ \text { Race/ethnicity ( } n=248) & \\ \text { Non-Hispanic white } & 203(82) \\ \text { Non-Hispanic black } & 12(5) \\ \text { Non-Hispanic other } & 15(6) \\ \text { Hispanic } & 18(7) \\ \text { Income ( } n=236 \text { ) } & \\ <139 \% \text { federal poverty level } & 52(22) \\ \geq 139 \% \text { to }<300 \% \text { federal poverty level } & 52(22) \\ \geq 300 \% \text { to }<400 \% \text { federal poverty level } & 20(8) \\ \geq 400 \% \text { federal poverty level } & 112(47)\end{array}$

\section{Characteristics of medical error}

Who experienced the error $(n=251)$

$\begin{array}{lr}\text { Self } & 83(33) \\ \text { Spouse or child } & 66(26) \\ \text { Other } & 102(41)\end{array}$

Responsible for medical care of individual who

experienced the error $(n=251)$

$\begin{array}{ll}\text { Yest } & 128(51) \\ \text { No } & 123(49)\end{array}$

When medical error occurred $(n=252)$

$\begin{array}{lr}<1 \text { year ago } & 60(24) \\ 1-2 \text { years ago } & 70(27) \\ 3-6 \text { years ago } & 122(49) \\ \text { Where medical error occurred }(n=253) & \\ \text { Hospital (not ER) } & 103(41) \\ \text { Ambulatory care/doctor's office } & 68(27) \\ \text { ER } & 39(15) \\ \text { Other (long-term care; pharmacy, dentist) } & 43(17)\end{array}$

*Numbers and percentages are adjusted by sampling weights to reflect the distribution of the adult population in Massachusetts.

tIncludes respondents who reported they personally experienced the error.

$E R$, emergency room.

the errors occurred in a hospital inpatient unit, while more than a quarter occurred in a doctor's office or clinic (table 1).

\section{Impact of medical errors over time}

When asked about the initial impact of the selfreported medical errors, 43\% (108/250) of respondents reported that they resulted in either death $(11 \%)$ or a significant adverse impact on physical health (32\%; table 2). Eighty-seven per cent (220/253)
Table 2 Initial impacts of medical error on patients and families $(n=253)$

\begin{tabular}{|c|c|c|c|}
\hline & & \multicolumn{2}{|c|}{ How long ago error occurred } \\
\hline & Full sample & $<1$ year ago & $3-6$ years ago \\
\hline & $\mathrm{n}(\%)$ & n (\%) & n (\%) \\
\hline Emotional* $^{*}$ & $(n=253) \dagger$ & $(n=60)$ & $(n=123)$ \\
\hline Sad & $133(53)$ & $30(50)$ & $70(57)$ \\
\hline Angry & $163(64)$ & $43(72)$ & $77(63)$ \\
\hline Anxious & $148(58)$ & $35(59)$ & $73(60)$ \\
\hline Depressed & $93(37)$ & $29(49)$ & $47(38)$ \\
\hline $\begin{array}{l}\text { Feeling abandoned or } \\
\text { betrayed by the doctors }\end{array}$ & $78(31)$ & $12(21)$ & $39(32)$ \\
\hline $\begin{array}{l}\text { Reported at least one } \\
\text { emotional impact }\end{array}$ & $220(87)$ & $50(86)$ & $104(88)$ \\
\hline Physical & $(n=250)$ & $(n=59)$ & $(n=121)$ \\
\hline Stay the same & $66(26)$ & $14(23)$ & $39(32)$ \\
\hline $\begin{array}{l}\text { Physical health slightly } \\
\text { impacted }\end{array}$ & $76(30)$ & $16(28)$ & $29(24)$ \\
\hline $\begin{array}{l}\text { Physical health strongly } \\
\text { impacted or died }\end{array}$ & $108(43)$ & $29(49)$ & $53(44)$ \\
\hline
\end{tabular}

reported at least one initial emotional impact, ranging from 31\% (78/253) who felt abandoned or betrayed by the doctors to $64 \%$ (163/253) who initially experienced anger (table 2). Respondents who perceived more severe physical impacts were significantly more likely to report each initial emotional impact except for anxiety (data not shown).

The initial physical and emotional impacts of the older and more recent self-reported errors were comparable (right panel of table 2). Although the persisting impacts of these errors lessen with the passage of time, they remain substantial years later (table 3). Forty-two per cent (20/48) of respondents who reported an error occurred in the year prior to the survey reported ongoing physical impacts, as did $27 \%(29 / 107)$ of respondents whose errors occurred 3-6 years ago (table 3 right panel). Similarly, 51\% $(63 / 123)$ of respondents whose self-reported errors occurred 3-6 years before the survey reported still experiencing at least one emotional impact at the time of the survey. Anger was the one emotional response significantly ameliorated by time; however, anger still affected over one-quarter of respondents.

The impact of perceived errors on healthcare avoidance and eroded trust persisted over time. Forty-five per cent (26/58) of all respondents whose errors occurred up to 1 year prior to the survey reported avoiding medical care, and two-thirds had lost trust in healthcare (table 3 right panel). These impacts remained high for respondents whose self-reported errors occurred 3-6 years before the survey (37\% $(42 / 115)$ and $67 \%(82 / 121)$, respectively).

Women were more likely to report long-term harms compared with men including anger, anxiety, 
Table 3 Persistent impacts of medical error on patients and families $(n=253)$

\begin{tabular}{|c|c|c|c|}
\hline & \multicolumn{3}{|c|}{ How long ago error occurred } \\
\hline & Full sample & $<1$ year ago & $3-6$ years ago \\
\hline & $\mathrm{n}(\% *)$ & n (\%) & $\mathrm{n}(\%)$ \\
\hline Emotionalt & $(n=253)$ & $(n=60)$ & $(n=123)$ \\
\hline Still sad & $59(23)$ & $16(26)$ & $32(26)$ \\
\hline Still angry & $84(33)$ & $26(44) \ddagger$ & $33(27)$ \\
\hline Still anxious & $74(29)$ & $20(33)$ & $41(33)$ \\
\hline Still depressed & $54(21)$ & $17(29)$ & $25(21)$ \\
\hline Still feeling abandoned or betrayed by the doctors & $50(20)$ & $11(18)$ & $31(26)$ \\
\hline Reported at least one emotional impact & $142(56)$ & $44(74) \ddagger$ & $63(51)$ \\
\hline Physical & $(n=220) \S$ & $(n=48)$ & $(n=107)$ \\
\hline Physical health still impacted $\S$ & $66(30)$ & $20(42)$ & $29(27)$ \\
\hline \multirow[t]{2}{*}{ Healthcare avoidance $\|^{* *} \dagger \dagger$} & ी & ** & $\dagger \dagger$ \\
\hline & $(n=213) \uparrow$ & $(n=52)^{* *}$ & $(n=102)+\dagger$ \\
\hline \multirow[t]{2}{*}{ Sometimes or always avoid doctor involved in error } & $122(57)$ & $26(50)$ & $59(57)$ \\
\hline & $(n=219) \uparrow$ & $(n=51)^{* *}$ & $(n=106)+\dagger$ \\
\hline \multirow[t]{2}{*}{ Sometimes or always avoid facility involved in error } & $123(56)$ & $23(45)$ & $60(57)$ \\
\hline & $(n=240) 9$ & $(n=58)^{\star *}$ & $(n=115) \dagger \dagger$ \\
\hline Sometimes or always avoid medical care in general & $91(38)$ & $26(45)$ & $42(37)$ \\
\hline Trust in healthcare & $(n=251)$ & $(n=59)$ & $(n=121)$ \\
\hline Less trusting of medical care now than before the error & $165(66)$ & $40(67)$ & $82(67)$ \\
\hline
\end{tabular}

*Percentages are adjusted by sampling weights to reflect the distribution of the adult population in Massachusetts. tRespondents could report more than one emotional impact.

$\neq \chi 2$ based on unweighted percentages is significant at $p \leq 0.05$.

$\S$ The sample size for physical health still impacted is $n=220$ because it excludes respondents who reported death.

१The sample size for sometimes or always avoid doctor involved in error is $n=213$, sometimes or always avoiding facility involved in error is $n=219$ and sometimes or always avoiding general medical care is $n=240$ since not applicable (N/A) was an option on these questions.

**The sample size for respondents who experienced an error less than a year ago and sometimes or always avoiding the doctor involved in error is $n=52$, sometimes or always avoiding facility involved in error is $n=51$ and sometimes or always avoiding general medical care is $n=58$ since N/A was an option on these questions.

††The sample size for respondents who experienced an error 3-6 years ago and sometimes or always avoiding the doctor involved in the error is $n=102$, sometimes or always avoiding facility involved in error is $n=106$ and sometimes or always avoiding general medical care is $n=115$ since N/A was an option on these questions.

feelings of abandonment, loss of trust in healthcare and avoiding the doctor involved in the error. Respondents with some college were more likely to report depression than those with less or more education; lower income respondents reported more anxiety and feeling abandoned; and respondents with lower education levels and lower incomes were more likely to avoid all medical care after the perceived error (data not shown).

\section{Open communication}

Respondents reported considerable variation in the openness with which the care team and facility staff communicated after the self-reported error (online supplementary appendix B table 5). Of the 246 responses to the individual questions used to develop the open communication index, the most common form of open communication received was the offer to ask questions about the error (46\%); the least prevalent was whether the event was acknowledged as an error (29\%). Thirty-one per cent reported getting information needed to understand how the medical error would impact their health, 34\% reported the care team spoke openly or truthfully about the error and 39\% reported they were given a chance to express feelings about the error and the care team spoke about the error in an easy to understand way.

An equal weighted count of each of the questions included in the open communication index yielded a Cronbach's alpha of 0.839 indicating high internal consistency. When categorising the elements of the open communication index into strata, 34\% reported that they received no communication about the error, $31 \%$ reported one to two elements of open communication, $12 \%$ three to four elements and $24 \%$ five to six elements.

\section{Association of reported impact with open communication}

Open communication was significantly associated with lower reported levels of most emotional and healthcare avoidance impacts still experienced at the time of the survey. Unadjusted bivariate comparisons suggest that this association was strongest when communication 

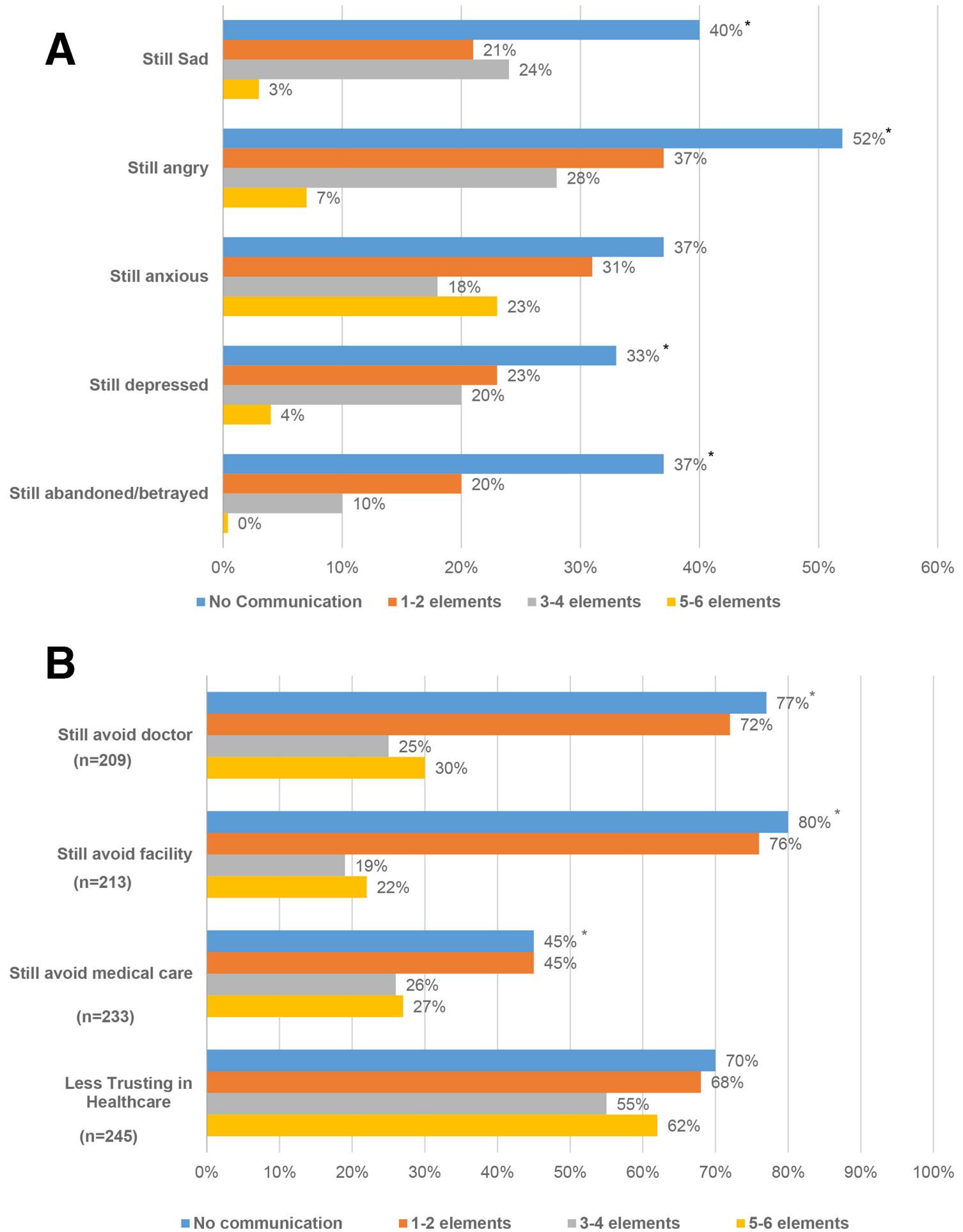

Figure 1 Impact of open communication on self-reported emotional impact, healthcare avoidance and loss of trust in healthcare. ${ }^{a}(A)$ Open communication and emotional impact at time of survey $(n=246) .{ }^{a}$ (B) Open communication and healthcare avoidance and loss of trust in healthcare at time of survey. ${ }^{a, b}$

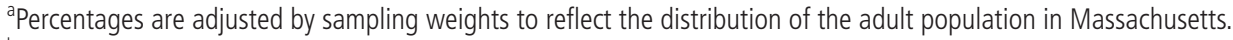

${ }^{b}$ The sample size for still avoiding doctor was $n=209$, still avoiding facility was $n=213$ and still avoiding medical care was $n=233$ since not applicable (N/A) was an option on these questions.

${ }^{*} \chi^{2}$ based on unweighted percentages is significant at $P \leq 0.05$.

was most open (figure 1). For respondents who experienced no communication, 33\%-52\% reported persistence of sadness, anger, depression and abandonment; for respondents reporting five to six aspects of open communication, prevalence was less than $10 \%$ (figure 1A). By contrast, open communication was less associated with a decline in anxiety over time. While $77 \%-80 \%$ of respondents who experienced 
no communication reported avoiding doctors and healthcare facilities involved in the self-reported error, avoidance was $30 \%$ or less among those who experienced five to six elements of open communication (figure 1B). Subanalyses examined each element of open communication to determine whether specific elements were associated with self-reported impact of error. There was no detectable pattern (data not shown).

In adjusted analyses that control statistically for both respondent characteristics as well as financial and physical harms induced by the perceived error, respondents who reported five to six elements of open communication had significantly lower odds of still being sad (OR $=0.17,95 \%$ CI 0.05 to 0.60$)$, depressed $(\mathrm{OR}=0.16,95 \% \mathrm{CI} 0.03$ to 0.77$)$ or feeling abandoned/betrayed (OR $=0.10,95 \% \mathrm{CI} 0.02$ to 0.48$)$ compared with respondents who reported no communication about the error (figure 2A); results for the full regression models are reported in online supplementary appendix $\mathrm{C}$ tables 8 and 9.

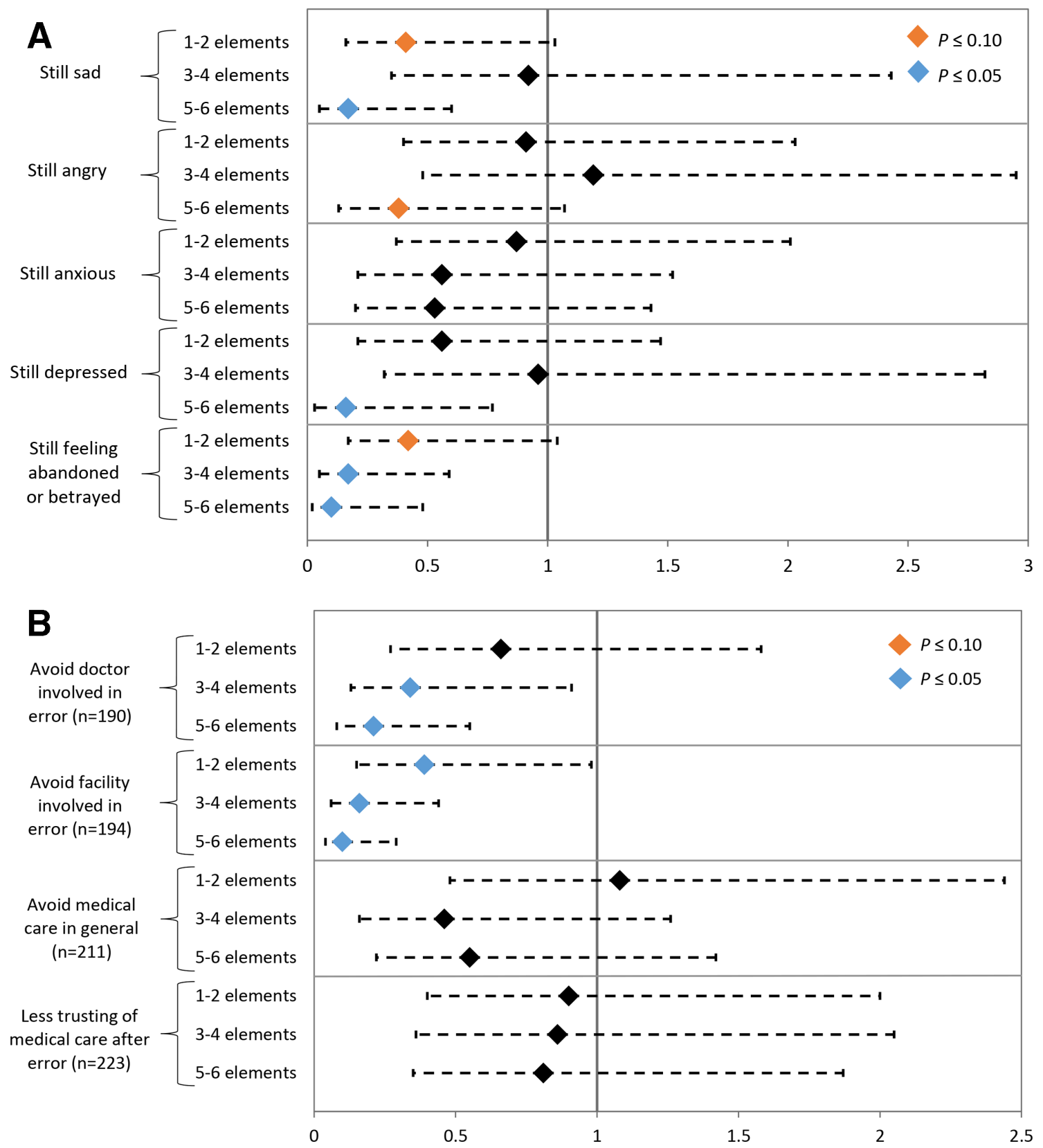

Figure 2 OR and 95\% Cl from logistic regression predicting persistent impacts of medical error in models excluding apology). (A) Open communication and emotional impact in models excluding apology $(n=224)$. (B) Open communication and healthcare avoidance in models excluding apology (logistic regression models also controlled for the initial financial and physical impacts of the error as well as other individual characteristics that might alter respondents' assessment of the error experience: who experienced the error, whether the respondent was responsible for the medical care of the individual who experienced the error, how long since the error occurred, gender and respondents' education level). Complete results are reported in the online supplementary appendix C table 8. 
Controlling statistically for other characteristics, respondents who experienced more open communication were also less likely to avoid the doctor(s) or facility involved in the self-reported error (figure 2B). For avoiding the doctor(s), these effects were evident when respondents experienced three or more elements of open communication $(\mathrm{OR}=0.34,95 \%$ CI 0.13 to 0.91 for three to four elements; OR $=0.21,95 \%$ CI 0.08 to 0.55 for five to six elements). The relationship was significant for facility avoidance when the respondent reported any element of open communication but the impact was progressively larger, the more elements of open communication that had been experienced $(\mathrm{OR}=0.39,95 \%$ CI 0.15 to 0.98 for one to two elements; OR $=0.16,95 \%$ CI 0.06 to 0.44 for three to four elements; OR $=0.10,95 \%$ CI 0.04 to 0.29 for five to six elements).

The association between open communication and persistent harm did not extend to all studied impacts (figure 2A,B). Exposure to open communication was not associated with lower levels of anxiety, overall avoidance of medical care or loss of trust in healthcare.

Nearly one in five respondents (47/252, 19\%) reported receiving an apology and $82 \%$ of those receiving an apology reported the apology was sincere (data not shown). Apology was more common when communication was more extensive (included more elements of open communication). However, only $45 \%(27 / 59)$ of respondents in the highest tier of open communication received an apology. In models controlling for apology, the impact of open communication persisted for some forms of emotional harm and healthcare avoidance. Controlling for apology, respondents who reported more elements of open communication had significantly lower odds of still being sad $(\mathrm{OR}=0.20,95 \%$ CI 0.05 to 0.77 for five to six elements) or feeling abandoned/betrayed $(\mathrm{OR}=0.24$, 95\% CI 0.07 to 0.87 for three to four elements; $\mathrm{OR}=0.19$, 95\% CI 0.04 to 1.01 for five to six elements) compared with respondents who reported no open communication about the self-reported error (figure 3A). Open communication bordered on significance for avoiding the doctor involved in the error and was significantly associated with reductions in reported avoidance of the facility involved in the error $(\mathrm{OR}=0.17,95 \%$ CI 0.06 to 0.47 for three to four elements; OR $=0.11,95 \%$ CI 0.04 to 0.35 for five to six elements: figure $3 \mathrm{~B}$ ) when controlling for apology. Results remained qualitatively similar when alternative weighting specifications of the open communication index were used (online supplementary appendix B table 6).

As shown in figure $3 \mathrm{~A}, \mathrm{~B}$, controlling for the extent of open communication, receiving an apology was independently associated with reduced levels of anxiety $(\mathrm{OR}=0.32,95 \% \mathrm{CI} 0.11$ to 0.90$)$, and bordered on significance for depression $(\mathrm{OR}=0.30,95 \%$ CI 0.07 to 1.20$)$ and feeling abandoned/betrayed $(\mathrm{OR}=0.20$,
95\% CI 0.04 to 1.06$)$. Similarly, apology significantly decreased the likelihood of avoiding all medical care $(\mathrm{OR}=0.28,95 \%$ CI 0.09 to 0.81$)$ and bordered on significance for avoiding the doctor involved in the self-reported error (OR $=0.40,95 \%$ CI 0.16 to 1.01 ). Apology appeared to be unrelated to sadness, anger, avoidance of the facility involved in the error and the restoration of trust in medical care following a perceived error experience.

Other covariates had anticipated relationships with self-reported error impact (online supplementary appendix $C$ tables 8 and 9). Respondents with substantial physical or financial impacts reported more frequent emotional impact and healthcare avoidance. Respondents who reported on the error experience of a family member and those who did not feel responsible for the medical care of that family member were less likely to report impacts compared with respondents who personally experienced the error. Similarly, sensitivity analyses excluding respondents who were not closely connected to the perceived error (eg, error affected an extended family member) did not qualitatively change the overall results between open communication and each of the emotional and healthcare avoidance outcomes.

\section{DISCUSSION}

Our findings highlight substantial persisting emotional harm, healthcare avoidance and loss of trust in healthcare among 253 patients and family members who self-reported an experience with medical error up to 6 years ago. Patients may continue to struggle after medical errors in ways that the medical community may not recognise. At the time of survey, at least onefifth of all respondents reported still experiencing each emotional impact, over half reported avoiding the doctor or facility involved, over a third reported still avoiding all medical care and two-thirds reported lost trust in healthcare. Even for respondents whose perceived errors occurred 3-6 years before the survey was administered, most still report at least one emotional impact (51\%), avoiding doctors (57\%) and facilities (57\%) involved, and lost trust in healthcare (67\%).

Open communication was associated with a reduction in many, though not all, of these persisting impacts. Notably, the effects of open communication often displayed pronounced threshold effects, being associated with significant reductions in emotional and behavioural impacts only if the interactions incorporated a sufficient number of elements of open communication. This effect was independent of whether or not that communication was associated with an explicit apology, though apologies were also independently associated with a reduction in some persisting impacts. Ideally communication after medical error would include both open communication about the event and an apology. Our data suggest that each plays an 


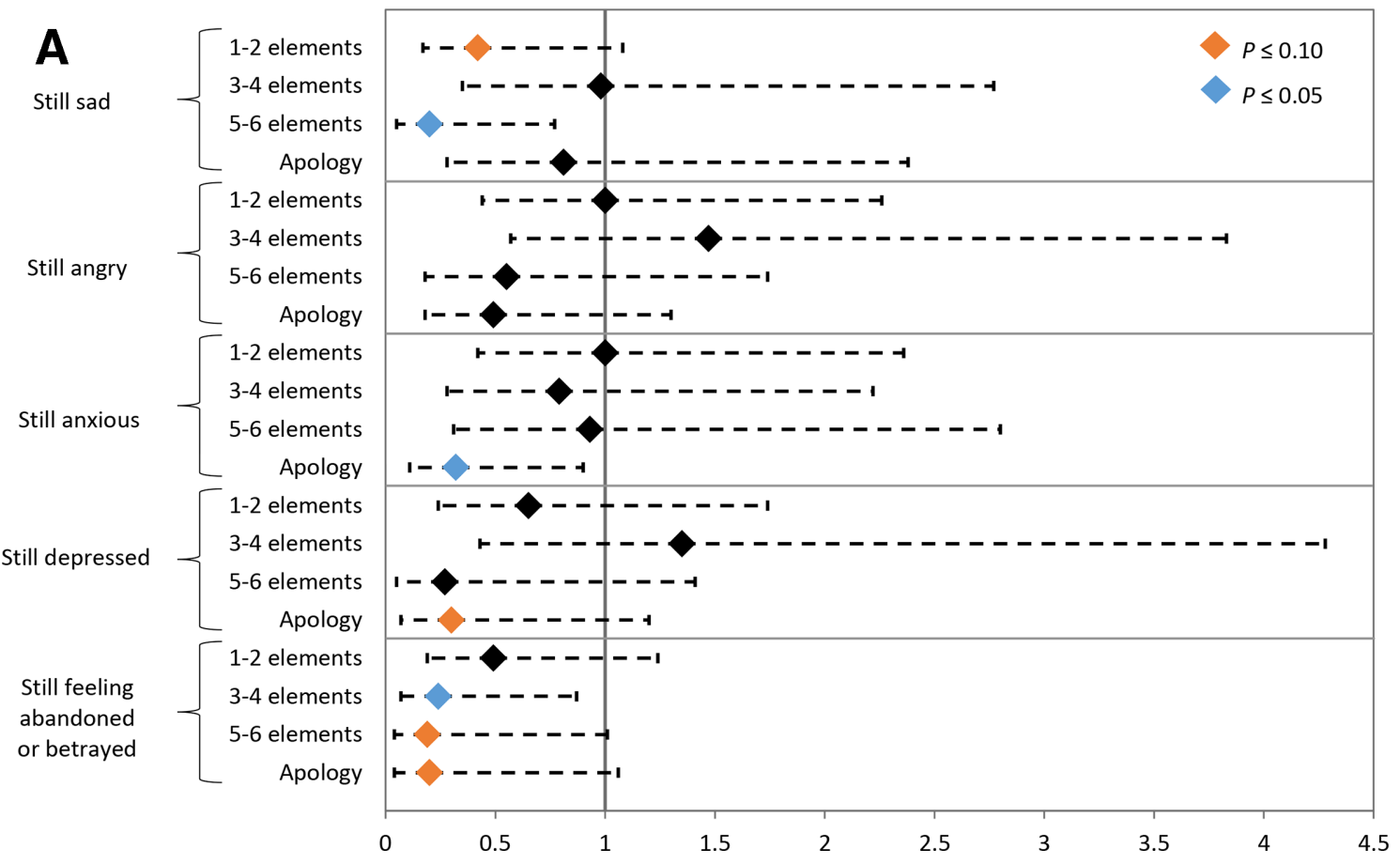

B

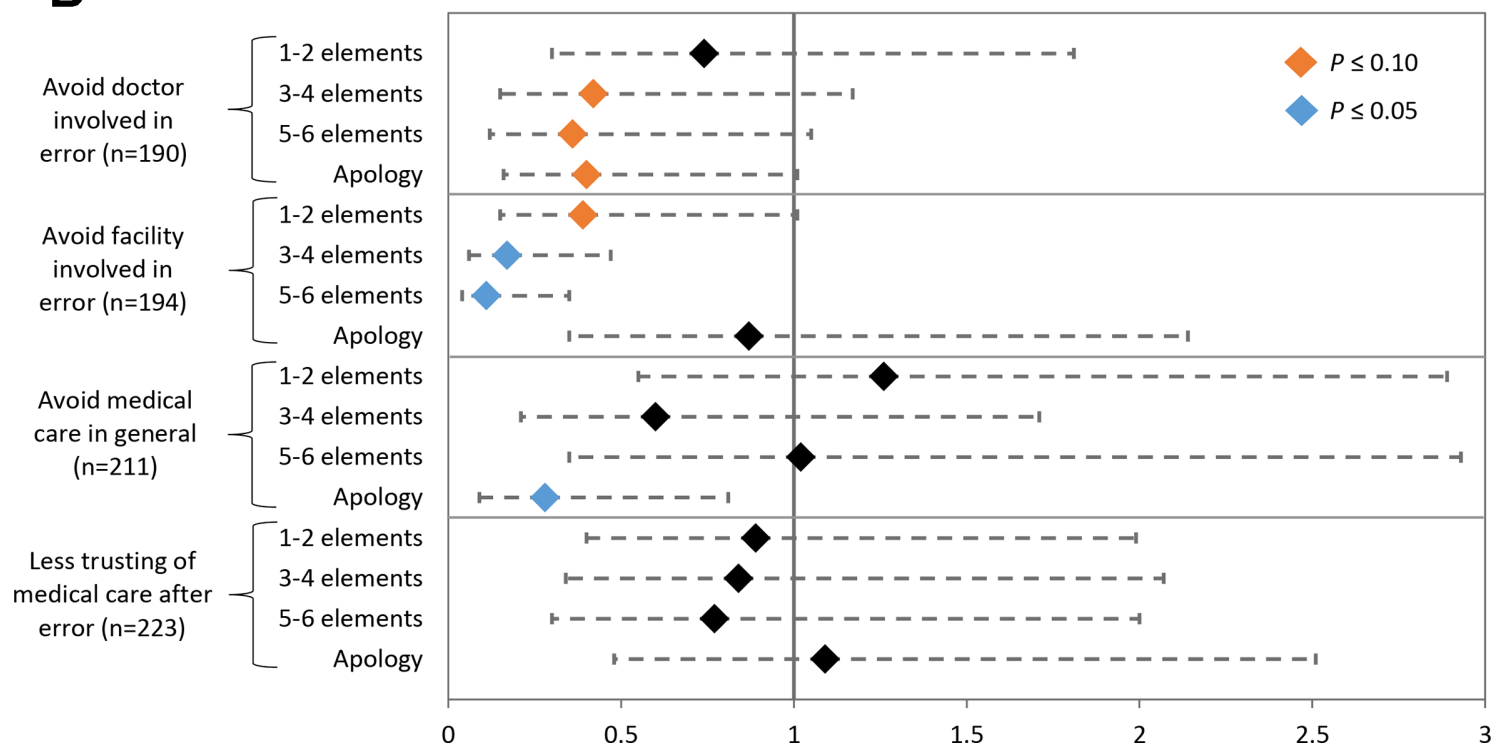

Figure 3 OR and 95\% Cl from logistic regression predicting persistent impacts of medical error in models including apology . (A) Open communication and emotional impact in models including apology $(n=224)$. (B) Open communication and healthcare avoidance in models including apology (logistic regression models also controlled for the initial financial and physical impacts of the error as well as other individual characteristics that might alter respondents' assessment of the error experience: who experienced the error, whether the respondent was responsible for the medical care of the individual who experienced the error, how long since the error occurred, gender and respondents' education level). Complete results are reported in the online supplementary appendix C table 9.

important independent role in potential long-term sequelae. Similarly, the results cannot be explained by additional disclosure or resolution practices that may be correlated with both open communication and outcomes. There were insufficient responses regarding the causes of the errors, steps taken to prevent future errors or compensation provided to explain away the relationship between open communication and longterm outcomes.
Our study has several limitations. All data, including the impacts of medical error, are derived from a selfreported survey. Reports of errors were not corroborated with clinicians or medical records. Nevertheless, previous research has found patients and families can identify medical errors effectively. ${ }^{33-35}$ Errors could be reported up to 6 years ago so not all respondents were surveyed close to their self-reported event. Consequently, the population responding may not be 
a representative of patients who feel that they have experienced a medical error in the immediate aftermath of the adverse events. The recontact survey was limited to Massachusetts adults with a $41 \%$ response rate $(10 \%$ when including the original MHIS response rate) and findings may not be generalisable to a broader population. However, we found minimal response bias (online supplementary appendix A tables 2-4) and the response rate is consistent with other state telephone surveys focused on healthcare. ${ }^{36-38}$ Our measure of open communication is not a validated index with known psychometric properties but it has a high Cronbach alpha, denoting sound internal consistency, and the association of open communication with respondent satisfaction measures following an error supports the construct validity of the index (online supplementary appendix B tables 6 and 7). Finally, the relationships identified above are statistical associations-one cannot presume causality. For example, emotional impacts could be due to apprehension about healthcare or anxiety about illness. The differing impact of open communication on a wide range of outcomes as well as several validation and sensitivity tests strengthens our confidence in the findings.

These findings are consistent with other studies suggesting that emotional and psychological consequences of errors-including grief and loss of trust in healthcare or altered healthcare-seeking behavioursmay persist long after the adverse event. ${ }^{6716}$ For example, Wagner et al found that veterans who were notified of a large-scale adverse dental event were less likely to use both the type of service that led to the adverse event and services unrelated to the event for up to 18 months. ${ }^{39}$ These results are similar to our findings that individuals avoid the doctor or facility involved in the self-reported error, suggesting the patients may 'vote with their feet' and shift providers. Even more concerning is the considerable proportion of respondents who report avoiding any medical care after a perceived error. Such avoidance could delay diagnosis and recovery for a wide range of health conditions. ${ }^{40-44}$

Our findings have several policy implications. Patient and families prefer to hear about medical errors. $^{11} 14 \quad 15 \quad 45$ Despite expert recommendations highlighting the importance of full disclosure, ${ }^{10} 4647$ patient and family experience with open communication varies widely in the aftermath of medical errors. Communication and resolution programmes (CRP), not yet widely implemented, could increase open communication through structured disclosure practices, reducing some of the negative impact of medical error on patients and families. These programmes facilitate transparent conversations about disclosures and apology, and provide compensation for patient injuries when appropriate. ${ }^{18} 4849$ In addition, CRPs may need to adopt a comprehensive communication approach that acknowledges the error, explains what happened and why, provides an apology and compensation where appropriate and explains how recurrences will be prevented, and: (1) acknowledges the long-term impacts of errors; (2) provides support for long-term emotional impacts; and (3) facilitates longterm care continuity to address the physical, emotional and healthcare-related behavioural consequences of the error either within the organisation or elsewhere, depending on patient preferences.

But open communication is not a panacea. Our findings suggest that it does not protect against persistent anxiety, avoiding medical care in general, or loss of trust in healthcare. All three outcomes reflect a common factor-lost faith in the efficacy and safety of medical care. Even when the healthcare system provides comprehensive, open communication about the error, patients may continue to experience anxiety and loss of trust now that they have a lived experience with what could go wrong. Apologies appear to help with some of these outcomes (anxiety and healthcare avoidance), but not others (loss of trust). Our results underscore the need for longitudinal research to better understand these long-term impacts and evidencebased approaches to better support harmed patients and families more comprehensively.

This study identifies substantial persistent emotional and healthcare avoidance impacts due to self-reported medical error and is the first to our knowledge to identify an association between open communication and the mitigation of these impacts. It also highlights long-term negative perceptions following medical error such as reduced trust and the inability of open communication alone to mitigate these perceptions. Healthcare organisations should increase investment in open communication and apology after a medical error to mitigate emotional and healthcare avoidance impacts and consider multifaceted interventions to address negative healthcare perceptions.

\section{Author affiliations \\ ${ }^{1}$ Betsy Lehman Center for Patient Safety, Boston, Massachusetts, USA \\ 2Patient Safety and Quality Initiatives, Beth Israel Deaconess Medical Center, \\ Boston, Massachusetts, USA \\ ${ }^{3}$ Harvard Medical School, Boston, Massachusetts, USA \\ ${ }^{4}$ UTHealth-Memorial Hermann Center for Healthcare Quality and Safety, University of Texas Health Science Center at Houston, Houston, Texas, USA \\ ${ }^{5}$ The Commonwealth Fund, New York, New York, USA \\ ${ }^{6}$ Tufts Medical Center, Tufts University School of Medicine, Boston, \\ Massachusetts, USA \\ ${ }^{7}$ Center for Surgery and Public Health, Brigham and Women's Hospital, Boston, Massachusetts, USA \\ ${ }^{8}$ Health Policy and Management, School of Public Health, Yale University, New} Haven, Connecticut, USA

Correction notice The article has been corrected since it was published online first. The acknowledgements section has been added in the paper.

Acknowledgements The authors thank the Betsy Lehman Center for Patient Safety for conceiving and leading the initiative, funding the survey and convening the authors and other contributors including: Jeff Brady and Caren Ginsburg of the Agency for Healthcare Research and Quality; Patricia 
McGaffigan of the Institute for Healthcare Improvement, Houng Trieu and $\mathrm{Zi}$ Zhang of the Center for Health Information and Analysis; and the SSRS survey team led by David Dutwin. In particular, the authors thank the Betsy Lehman Center's Executive Director, Barbara Fain, Deputy Director, ME Malone and Data Analyst, Natalia Ciesielska.

Contributors All authors except JCP participated in the original design of the recontact survey including providing technical expertise regarding medical errors. All authors participated in the design of the study. JCP analysed the data. JCP and MS had access to the data and drafted the manuscript. All other authors provided critical revision of the manuscript.

Funding The authors have not declared a specific grant for this research from any funding agency in the public, commercial or not-for-profit sectors.

Competing interests None declared.

Patient consent for publication Not required.

Ethics approval Solutions IRB approved both surveys.

Provenance and peer review Not commissioned; externally peer reviewed.

Data availability statement Data are available upon reasonable request. Please contact the corresponding author to discuss the feasibility of obtaining access to a deidentified data set.

\section{ORCID iD}

Julia C Prentice http://orcid.org/0000-0003-2620-3685

\section{REFERENCES}

1 Kohn LT, Corrigan JM, Donaldson MS. To err is human: building a safer health system. Washington DC: national Academy of sciences, 2000. Available: https://www.ncbi.nlm. nih.gov/pubmed/25077248

2 Panagioti M, Khan K, Keers RN, et al. Prevalence, severity, and nature of preventable patient harm across medical care settings: systematic review and meta-analysis. BMJ 2019;51:14185.

3 Van Den Bos J, Rustagi K, Gray T, et al. The \$17.1 Billion Problem: The Annual Cost Of Measurable Medical Errors. Health Aff 2011;30:596-603.

4 NORC at the University of Chicago, IHI/NPSF Lucian Leape Institute. Americans' Experiences with Medical Errors and Views on Patient Safety. Cambridge, MA: Institute for Healthcare Improvement and NORC at the University of Chicago, 2017: 38. www.ihi.org/about/news/Documents/IHI NPSF_NORC_Patient_Safety_Survey_2017_Final_Report.pdf

5 Harvard School of Public Health. The Public's Views on Medical Error in Massachusetts. Boston, MA: Betsy Lehman Center for Patient Safety and Health Policy Commission, 2014: 47. https://www.betsylehmancenterma.gov/assets/ uploads/blc-hsph-research-report.pdf

6 Ottosen MJ, Sedlock EW, Aigbe AO, et al. Long-Term impacts faced by patients and families after harmful healthcare events. $J$ Patient Saf 2018:1.

7 Southwick FS, Cranley NM, Hallisy JA. A patient-initiated voluntary online survey of adverse medical events: the perspective of 696 injured patients and families. BMJ Qual Saf 2015;24:620-9.

8 Delbanco T, Bell SK. Guilty, afraid, and alone — struggling with medical error. N Engl J Med 2007;357:1682-3.

9 Fisher KA, Ahmad S, Jackson M, et al. Surrogate decision makers' perspectives on preventable breakdowns in care among critically ill patients: A qualitative study. Patient Educ Couns 2016;99:1685-93.

10 Elwy AR, Itani KMF, Bokhour BG, et al. Surgeons' disclosures of clinical adverse events. JAMA Surg 2016;151:1015-21.
11 Gallagher TH, Waterman AD, Ebers AG, et al. Patients' and physicians' attitudes regarding the disclosure of medical errors. JAMA 2003;289:1001-7.

12 Iezzoni LI, Rao SR, DesRoches CM, et al. Survey shows that at least some physicians are not always open or honest with patients. Health Aff 2012;31:383-91.

13 Iedema R, Allen S, Britton K, et al. Patients' and family members' views on how clinicians enact and how they should enact incident disclosure: the "100 patient stories" qualitative study. BMJ 2011;343:d4423.

14 Gallagher TH, Studdert D, Levinson W. Disclosing harmful medical errors to patients. N Engl J Med 2007;356:2713-9.

15 Gallagher TH, Garbutt JM, Waterman AD, et al. Choosing your words carefully: how physicians would disclose harmful medical errors to patients. Arch Intern Med 2006;166:1585-93.

16 Bell SK, Etchegaray JM, Gaufberg E, et al. A MultiStakeholder Consensus-Driven research agenda for better understanding and supporting the emotional impact of harmful events on patients and families. Jt Comm J Qual Patient Saf 2018;44:424-35.

17 Mazor K, Roblin DW, Greene SM, et al. Primary care physicians' willingness to disclose oncology errors involving multiple providers to patients. BMJ Qual Saf 2016;25:787-95.

18 Boothman RC, Blackwell AC, Campbell DA, et al. A better approach to medical malpractice claims? the University of Michigan experience. J Health Life Sci Law 2009;2:125-59.

19 Kachalia A, Kaufman SR, Boothman R, et al. Liability claims and costs before and after implementation of a medical error disclosure program. Ann Intern Med 2010;153:213-21.

20 Moore J, Mello MM. Improving reconciliation following medical injury: a qualitative study of responses to patient safety incidents in New Zealand. BMJ Qual Saf 2017;26:788-98.

21 Moore J, Bismark M, Mello MM. Patients' experiences with Communication-and-Resolution programs after medical injury. JAMA Intern Med 2017;177:1595-603.

22 Ock M, Choi EY, Jo M-W, et al. Evaluating the expected effects of disclosure of patient safety incidents using hypothetical cases in Korea. PLoS One 2018;13:e0199017.

23 Solutions IRB. Homepage [Internet]. Yarnell (AZ): Solutions IRB, 2019. Available: https://www.solutionsirb.com/ [Accessed 19 Jul 2019].

24 Henry J Kaiser Family Foundation [Internet]. San Francisco (Ca): KFF; 2006. summary and Chartpack: 2006 update on consumers' views of patient safety and quality information, 200620 slides]. Available from:. Available: https://www.kff.org/ other/poll-finding/summary-and-chartpack-2006-update-onconsumers/ [Accessed 19 Jul 2019].

25 Collaborative for Accountability and Improvement. About Us [Internet]. Seattle (WA): Collaborative Accountability and Improvement, 2017. Available: http://communicationandreso lution.org/about-us/ [Accessed 19 Jul 2019].

26 Costs of Care [Internet]. Boston (MA): costs of care; 2017. Tallying the high cost of preventable harm, 2017. Available: https://costsofcare.org/tallying-the-high-cost-of-preventableharm/ [Accessed 19 Jul 2019].

27 Mello MM, Studdert DM, Thomas EJ, et al. Who pays for medical errors? an analysis of adverse event costs, the medical liability system, and incentives for patient safety improvement. J Empir Leg Stud 2007;4:835-60.

28 Shreve J, Van Den Bos J, Gray T, et al. The economic measurement of medical errors. Seattle, WA: Society of 
Actuaries, 2010: 54. https://www.soa.org/globalassets/assets/ Files/Research/Projects/research-econ-measurement.pdf

29 Stoyanova RG, Raycheva RD, Dimova RT. Economic aspects of medical errors. Folia Med 2012;54:58-64.

30 STATA [computer program]. Version 15.0. College Station (tx): STATA; 1996-2019. data analysis and statistical software. Available: https://www.stata.com/

31 The American Association for the Public Opinion Research. Standard definitions: final dispositions of case codes and outcome rates for surveys. Oakbrook Terrace (IL: AAPOR, 2016: 81. www.aapor.org/AAPOR_Main/media/publications/ Standard-Definitions20169theditionfinal.pdf22

32 SSRS. Massachusetts medical error recontact survey. Boston, MA: Prepared for Betsy Lehman Center for Patient Safety, 2018: 41.

33 Weissman JS, Schneider EC, Weingart SN, et al. Comparing patient-reported Hospital adverse events with medical record review: do patients know something that hospitals do not? Ann Intern Med 2008;149:100-8.

34 Khan A, Furtak SL, Melvin P, et al. Parent-Reported errors and adverse events in hospitalized ChildrenParent-Reported errors and adverse events in hospitalized ChildrenParent-Reported errors and adverse events in hospitalized children. JAMA Pediatr 2016;170:e154608.

35 Bell SK, Gerard M, Fossa A, et al. A patient feedback reporting tool for OpenNotes: implications for patientclinician safety and quality partnerships. BMJ Qual Saf 2017;26:312-22.

36 SSRS [Internet]. Glen Mills (PA): SSRs; 2019. nonresponse and bias trends in Telephonic probability sample, 2018. Available: https://ssrs.com/nonresponse-and-bias-trends-in-telephonicprobability-samples/ [Accessed 19 Jul 2019].

37 Davern M. Nonresponse rates are a problematic indicator of nonresponse bias in survey research. Health Serv Res 2013;48:905-12.

38 Johnson TP, Wislar JS. Response rates and nonresponse errors in surveys. JAMA 2012;307:1805-6.

39 Wagner TH, Taylor T, Cowgill E, et al. Intended and unintended effects of large-scale adverse event disclosure: a controlled before-after analysis of five large-scale notifications. BMJ Qual Saf 2015;24:295-302.

40 Taber JM, Leyva B, Persoskie A. Why do people avoid medical care? A qualitative study using national data. J Gen Intern Med 2015;30:290-7.

41 Kannan VD, Veazie PJ. Predictors of avoiding medical care and reasons for avoidance behavior. Med Care 2014;52:336-45.

42 Byrne SK. Healthcare avoidance: a critical review. Holist Nurs Pract 2008;22:280-92.

43 Richards MA, Westcombe AM, Love SB, et al. Influence of delay on survival in patients with breast cancer: a systematic review. The Lancet 1999;353:1119-26.

44 Perkins DO, Gu H, Boteva K, et al. Relationship between duration of untreated psychosis and outcome in First-Episode schizophrenia: a critical review and meta-analysis. Am J Psychiatry 2005;162:1785-804.

45 A Consensus Statement of the Harvard Hospitals. When things go wrong: responding to adverse events. Cambridge (MA: Massachusetts Coalition for the Prevention of Medical Errors, 2006: 42. http://www.macoalition.org/documents/respondi ngToAdverseEvents.pdf

46 National Quality Forum. Safe practices for better Healthcare-2010 update: a consensus report. Washington DC: National Quality Forum, 2010: 446. http://www.qualityforum. org/Publications/2010/04/Safe_Practices_for_Better_ Healthcare_\%E2\%80\%93_2010_Update.aspx

47 Agency for Healthcare Research and Quality [Internet]. Rockville (MD): U.S. department of health and human services; 2016. communication and optimal resolution (CANDOR) toolkit, 2017. Available: https://www.ahrq.gov/ professionals/quality-patient-safety/patient-safety-resources/ resources/candor/introduction.html [Accessed 19 Jul 2019].

48 MACRMI. Welcome [Internet]. Massachusetts: MACRMI, 2019. Available: https://www.macrmi.info/ [Accessed 19 Jul 2019].

49 Bell SK, Smulowitz PB, Woodward AC, et al. Disclosure, apology, and offer programs: stakeholders' views of barriers to and strategies for broad implementation. Milbank $Q$ 2012;90:682-705. 